\title{
Cytogenetic Map
}

National Cancer Institute

\section{Source}

National Cancer Institute. Cytogenetic Map. NCI Thesaurus. Code C15717.

The visual appearance of a chromosome when stained and examined under a

microscope. Particularly important are visually distinct regions, called light and dark bands, which give each of the chromosomes a unique appearance. This feature allows a person's chromosomes to be studied in a clinical test known as a karyotype, which allows scientists to look for chromosomal alterations. (NHGRI Glossary of Genetic Terms) 